\title{
Endoscopic sleeve gastroplasty for severe obesity by full-thickness suturing using the GERDX device
}
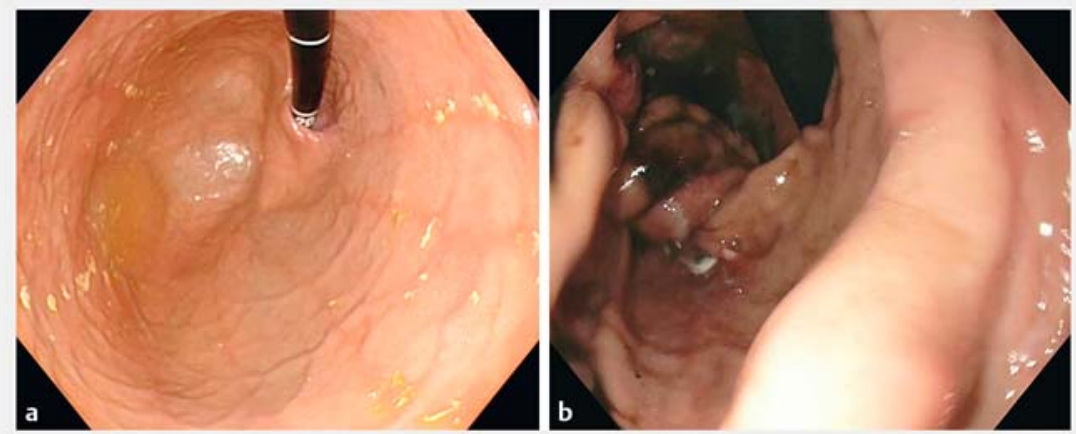

- Fig. 1 Endoscopic view of the stomach before and after the application of 18 transmural sutures using the GERDX device (G-Surg GmbH, Seeon-Seebruck, Germany), showing the reduction in gastric volume. a Before the procedure. $\mathbf{b}$ After the procedure.
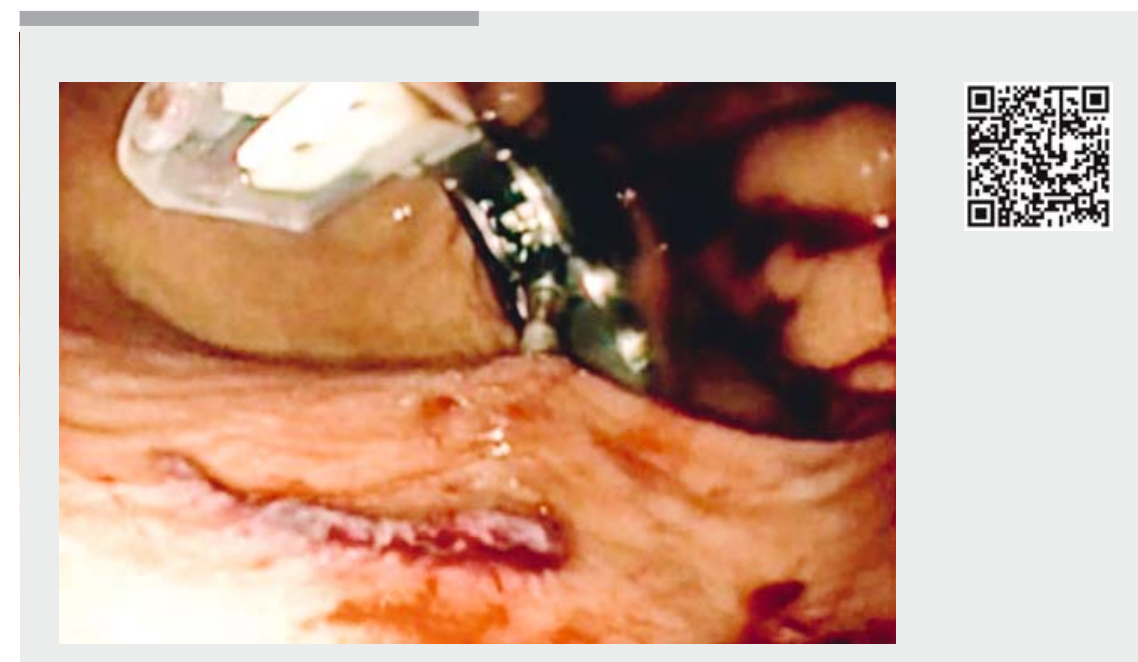

$\checkmark$ Video 1 A new treatment option for obesity. Use of the GERDX device (G-Surg GmbH, Seeon-Seebruck, Germany) for application of transmural sutures in the stomach in order to perform endoscopic sleeve gastroplasty.

Obesity is an increasing health problem worldwide. Endoscopic therapies have emerged as treatment option in addition to lifestyle modification and bariatric surgery. One possible endoscopic approach is to reduce the size of the stomach [1, 2]. This approach has been demonstrated to be feasible and efficient using different endoscopic suturing devices [3,4]. The GERDX device (G-Surg GmbH, Seeon-
Seebruck, Germany) allows full-thickness suturing in the upper gastrointestinal tract and was originally used for endoscopic antireflux therapy [5]. The transmural sutures have proven to be durable and to remain in situ even after long follow-up.

In this 41-year old woman, who suffered from severe obesity $(168 \mathrm{~cm}, 121 \mathrm{~kg}$, body mass index [BMI] $42.9 \mathrm{~kg} / \mathrm{m}^{2}$ ), we

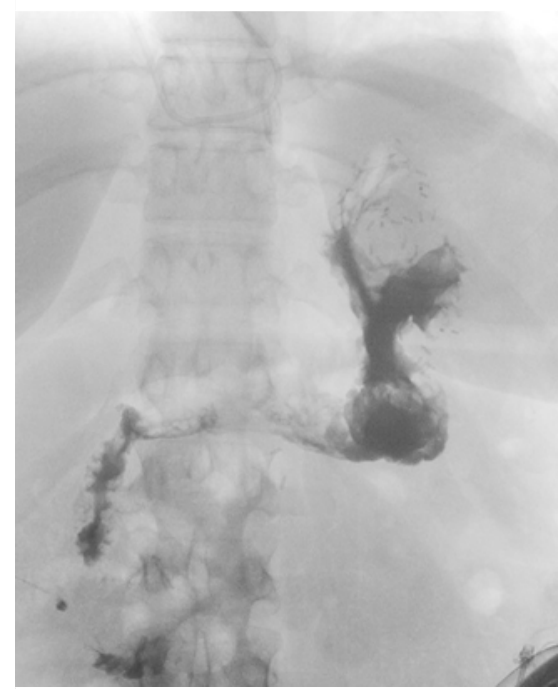

- Fig. 2 Contrast swallow two days after endoscopic sleeve gastroplasty, confirming the sleeve configuration of the stomach and showing no signs of perforation.

aimed to use the GERDX device to perform an endoscopic sleeve gastroplasty. The device was inserted into the stomach and an ultraslim endoscope was introduced through the device's working channel to provide visualization. Next, the gastric wall was retracted with a tissue retractor and the full-thickness suture was applied. This was repeated 18 times from the fundus to the distal corpus ( $\triangleright$ Video 1$)$. This resulted in a markedly reduced stomach volume.

The procedure was performed under general anesthesia and peri-interventional antibiotic therapy was initiated. The gastric volume reduction was successfully performed using the GERDX device ( $\triangleright$ Fig. 1 ) and no procedure-related complications occurred.

The next day a control endoscopy was performed, which confirmed the volume reduction and showed no signs of bleeding or perforation. A contrast swallow test confirmed the sleeve configuration of the stomach ( $\triangleright$ Fig.2). A normal diet was resumed within days and the patient 
was discharged on Day 5 without any further complications.

After 8 weeks, the patient had lost $12 \mathrm{~kg}$ of weight, resulting in a change in BMI of $-4.3 \mathrm{~kg} / \mathrm{m}^{2}$ or a percent excess weight loss of $24.0 \%$.

Endoscopic sleeve gastroplasty using the GERDX device was feasible, safe, and efficient in this patient. This technique could potentially emerge as a minimally invasive treatment for obesity.

\section{Endoscopy_UCTN_Code_TTT_1AO_2AJ}

\section{Competing interests}

None

\section{The authors}

Andreas Wannhoff', Christopher Hofmann', Benjamin Meier ${ }^{1}$, Dieter Birk ${ }^{2}$, Karel Caca ${ }^{1}$

1 Internal Medicine I, Klinikum Ludwigsburg, Ludwigsburg Germany

2 Department of General and Visceral Surgery, Krankenhaus Bietigheim, BietigheimBissingen, Germany
Corresponding author

\section{Karel Caca, MD}

Internal Medicine I, Klinikum Ludwigsburg, Posilipostrasse 4, 71640 Ludwigsburg,

Germany

Fax: +49-7141-9967219

Karel.Caca@kliniken-lb.de

\section{References}

[1] Kumar N. Endoscopic therapy for weight loss: gastroplasty, duodenal sleeves, intragastric balloons, and aspiration. World J Gastrointest Endosc 2015; 7: 847-859

[2] ASGE Bariatric Endoscopy Task Force; ASGE Technology Committee, Abu Dayyeh BK et al. Endoscopic bariatric therapies. Gastrointest Endosc 2015; 81: 1073 - 1086

[3] Sharaiha RZ, Kedia P, Kumta N et al. Initial experience with endoscopic sleeve gastroplasty: technical success and reproducibility in the bariatric population. Endoscopy 2015; 47: $164-166$

[4] Espinos JC, Turro R, Mata A et al. Early experience with the Incisionless Operating Platform (IOP) for the treatment of obesity: the Primary Obesity Surgery Endolumenal (POSE) procedure. Obes Surg 2013; 23: $1375-1383$

[5] von Renteln D, Schiefke I, Fuchs KH et al. Endoscopic full-thickness plication for the treatment of GERD by application of multiple Plicator implants: a multicenter study (with video). Gastrointest Endosc 2008; 68: $833-844$

\section{Bibliography}

DOI https://doi.org/10.1055/a-0756-7921

Published online: 11.12 .2018

Endoscopy 2019; 51: E34-E35

(c) Georg Thieme Verlag KG

Stuttgart · New York

ISSN 0013-726X

\section{ENDOSCOPY E-VIDEOS}

https:/|eref.thieme.de/e-videos

回回 Endoscopy E-Videos is a free access online section, reporting 靣转: on interesting cases and new

techniques in gastroenterological endoscopy. All papers include a high quality video and all contributions are freely accessible online.

This section has its own submission website at https://mc.manuscriptcentral.com/e-videos 